\title{
RESEARCH ON SELECTION OF ABRASIVE GRAIN SIZE AND CUTTING PARAMETERS WHEN GRINDING OF INTERRUPTED SURFACE USING ALUMINUM OXIDE GRINDING WHEEL WITH CERAMIC BINDER
}

\author{
Do Duc Trung $\bowtie$ \\ Faculty of Mechanical Engineering ${ }^{1}$ \\ doductrung@haui.edu.vn \\ Le Dang $\mathrm{Ha}$ \\ Center for Mechanical Engineering ${ }^{l}$ \\ ${ }^{1}$ Hanoi University of Industry \\ 298 Cau Dien str., Bac Tu Liem District, Hanoi, Vietnam, 100000
}

$\bowtie$ Corresponding author

\begin{abstract}
In this article, a study on intermittent surface grinding using aluminum oxide grinding wheel with ceramic binder is presented. The testing material is 20XH3A steel (GOST standard - Russian Federation). The testing sample has been sawn 6 grooves, with the width of each groove of $10 \mathrm{~mm}$, the grooves are evenly distributed on the circumference of sample. The testing sample resembles a splined shaft. An experimental matrix of nine experiments has been built by Taguchi method, in which abrasive grain size, workpiece speed, feed rate and depth of cut were selected as input variables. At each experiment, surface roughness $(R a)$ and roundness error $(R E)$ have been measured. Experimental results show that the aluminum oxide and ceramic binder grinding wheels are perfectly suitable for grinding intermittent surface of 20XH3A steel. Data Envelopment Analysis based Ranking (DEAR) method has been used to solve the multi-objective optimization problem. The results also showed that in order to simultaneously ensure minimum surface roughness and $R E$, abrasive grain size is $80 \mathrm{mesh}$, workpiece speed is $910 \mathrm{rpm}$, feed rate is $0.05 \mathrm{~mm} / \mathrm{rev}$ and depth of cut is $0.01 \mathrm{~mm}$. If evaluating the grinding process through two criteria including surface roughness and $R E$, depth of cut is the parameter having the greatest effect on the grinding process, followed by the influence of feed rate, workpiece speed, and abrasive grain is the parameter having the least effect on the grinding process. In addition, the effect of each input parameter on each output parameter has also been analyzed, and orientations for further works have also been recommended in this article.
\end{abstract}

Keywords: Interrupted surface workpiece, external cylindrical grinding, aluminum oxide grinding wheel, ceramic binder.

DOI: $10.21303 / 2461-4262.2022 .002058$

\section{Introduction}

The grinding operation has a very important position in mechanical production. This method is used for machining surfaces with high accuracy requirements [1,2]. Among the grinding methods, external cylindrical grinding is a highly universal method, used to machine round surfaces such as center shaft to be fitted with bearings (ball bearings, plain bearings), splined shaft, gears, rollers, mangle, etc. However, if the studies of grinding of continuous surfaces have been done by many authors, the documents on interrupted surface grinding have been still very limited. Products with interrupted surfaces are usually made by grinding method such as engine piston ring, drill bits, gears, splined shaft, etc. [3-5]. However, as mentioned above, the studies in this area have been still very limited. Because of this, when cylindrically grinding of intermittent surfaces, there are many difficulties in finding reference documents. Despite great efforts in locating relevant documents, the authors of this article have found only a very limited number of studies on intermittent surface cylindrical grinding.

The research of external cylindrical plunge grinding on interrupted surface of AISI 4340 steel has been carried out in a number of studies, using different types of grinding wheels, such as using aluminum oxide grinding wheel with pine resin binder [6], using aluminum oxide grinding wheel with epoxy resin binder [7], using aluminum oxide grinding wheel with vitrified binder [8], and using CBN grinding wheel [9]. The results of these studies together have made the following 
conclusions: (1) both surface roughness and roundness error in interrupted surface grinding are higher than those in continuous surface grinding; (2) when increasing plunge-feed rate, both surface roughness and roundness error increase; (3) both surface roughness and roundness error increase when the number of grooves in the workpiece increases; (4) grinding wheel wear also increases when increasing plunge-feed rate and when increasing number of grooves on the grinding wheel; (5) and no damage to the grinding surface due to the impact of cutting heat was observed. However, all four works mentioned above are applicable to the case of cylindrical plunge-feed grinding, when the thickness of grinding wheel is greater than the length to be ground on workpiece surface. In fact, cylindrical longitudinal feed grinding is much more commonly used than cylindrical plunge-feed grinding because the length of surfaces to be ground is usually larger than the thickness of grinding wheel.

In [10], the authors have studied cylindrical longitudinal feed grinding of interrupted surface of AISI 4140 steel using aluminum oxide grinding wheel with a vitrified binder. This study has concluded: (1) workpiece speed affects surface roughness and roundness error more than depth, and the effect of number of grooves on workpiece on surface roughness and roundness error is the smallest among the three investigated parameters (workpiece speed, depth of cut and number of grooves); (2) both surface roughness and roundness error increase when increasing depth of cut, and when increasing number of grooves on workpiece. This study has also determined the optimal value of spindle speed, depth of cut, and number of grooves on workpiece to simultaneously ensure the same minimum surface roughness and roundness error. However, their research results show that the optimal value of number of grooves on grinding wheel is zero (i.e. continuous surface grinding), so it can be said that the research results in this work are not significant when applied to interrupted surface grinding.

Aluminum oxide grinding wheel has the advantage of low cost (compared to diamond grinding wheel or CBN grinding wheel), so it is very commonly used in grinding technology. Although it is known that compared to grinding wheels with resin binder or vitrified binder, grinding wheel with ceramic binder have the disadvantage of poor impact resistance, in fact, this grinding wheel is still commonly used both in the case of grinding of continuous surface and grinding of interrupted surface. However, so far, there have been no published studies on the use of aluminum oxide grinding wheel with ceramic binder for interrupted surface grinding. It is also from the above studies and other related documents [11-13] showing that surface roughness and roundness error are two of the parameters commonly used to evaluate the cylindrical grinding process. This is also easily explained because surface roughness is the parameter directly affecting wear resistance, endurance, and strength of joint, while roundness error is the parameter directly affecting accuracy of joint, thereby greatly affecting the workability and durability of the product.

Based on the inheritance and development of published studies, for the purpose of filling the gaps of unrealized interrupted surface grinding technology, in this article, let's study the process of cylindrical longitudinal feed grinding on interrupted surface by aluminum oxide grinding wheel with ceramic binder. The main purpose of this study is to determine the abrasive grain size and cutting parameters to simultaneously ensure the minimum surface roughness and the minimum roundness error.

\section{Materials and methods}

The testing sample is 20XH3A steel (GOST standard - Russian Federation), this is commonly used steel for manufacturing units such as gears, splined shafts, etc. These parts all require to be machined by grinding method. Fig. 1 shows the cross section of workpiece with 6 grooves. The length of workpiece is $300 \mathrm{~mm}$, in which the two ends of workpiece with a diameter of $40 \mathrm{~mm}$ are the positions used to mount and place the workpiece on the grinder, the part of workpiece diameter for grinding is $50 \mathrm{~mm}$ in diameter. The size of external diameter of workpiece as well as the number of grooves and the size of grooves on workpiece are similar to the size of splined shaft in the gear-box of a number of machine tools [14].

These splined shafts are both responsible for transmitting motion between the shafts and serving as a guide for the gears when moving to change the speed of driver unit. These shafts are fitted with gears (or hub) in a centered manner equal to the external diameter of the shaft [15]. Therefore, the outer surface of shaft is required to have a small roughness and roundness error, so 
these parts often require to be machined by grinding method both during manufacture and during repair. In order to create these workpieces, the operations of center hole drilling, outer cylindrical surface turning, groove milling, heat treatment (after heat treatment, the workpiece hardness reaches $60 \pm 1 \mathrm{HRC}$ ), and rough grinding have been used.

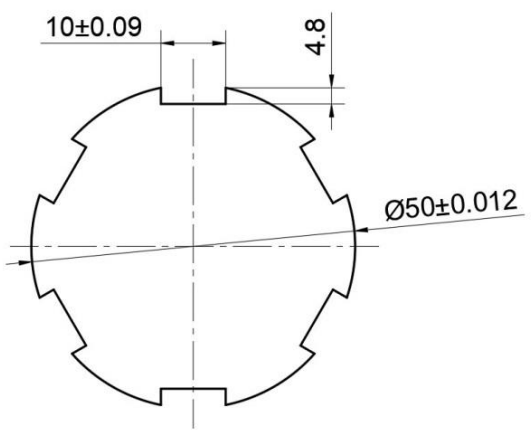

Fig. 1. Cross section of the workpiece

The tests have been conducted on a traditional grinder with six values of spindle speed (including: 80, 160, 165, 330, 250 and $500 \mathrm{rpm}$ ). Three types of grinding wheel with ceramic binder have been used during the experiment. The only difference between the three types of grinding wheel is in the abrasive grain size. The full symbols of the three types of grinding wheel are $C_{n} 46 \cdot G \cdot V_{1} \cdot T B_{2} 300 \times 40 \times 140 \times 35 \mathrm{~m} / \mathrm{s}, C_{n} 60 \cdot G \cdot V_{1} \cdot T B_{2} 300 \times 40 \times 140 \times 35 \mathrm{~m} / \mathrm{s}$, and $C_{n} 80 \cdot G \cdot V_{1} \cdot T B_{2}$ $300 \times 40 \times 140 \times 35 \mathrm{~m} / \mathrm{s}$. The meaning of each component is the symbol of grinding wheel is as follows: $C_{n}$ is the symbol indicating the type of abrasive grain material as aluminum oxide; 46,60 or 80 is the parameter indicating the abrasive grain size, i.e. the number of meshes per square inch of classifying screen; $G$ describes the ceramic binder; $V_{1}$ describes the type of cylindrical grinding wheel; $T B_{2}$ describes the type of grinding wheel with an average hardness of level 2 out of 3 levels; external diameter, thickness and internal diameter of grinding wheel are $300 \mathrm{~mm}$, $40 \mathrm{~mm}$ and $140 \mathrm{~mm}$, respectively; in accordance with the recommendation of grinding wheel manufacturers, these type of grinding wheels should not be used when the cutting speed is greater than $35 \mathrm{~m} / \mathrm{s}$ for the safety of operator and the safety of equipment. This is a low-cost grinding wheel, used in many grinding methods (cylindrical grinding, centerless grinding, surface grinding) to grind a variety of materials [16].

During the grinding process, the workpiece is mounted on two quills, and the torques is transmitted from the main shaft to the workpiece through the rest mechanism (Fig. 2).

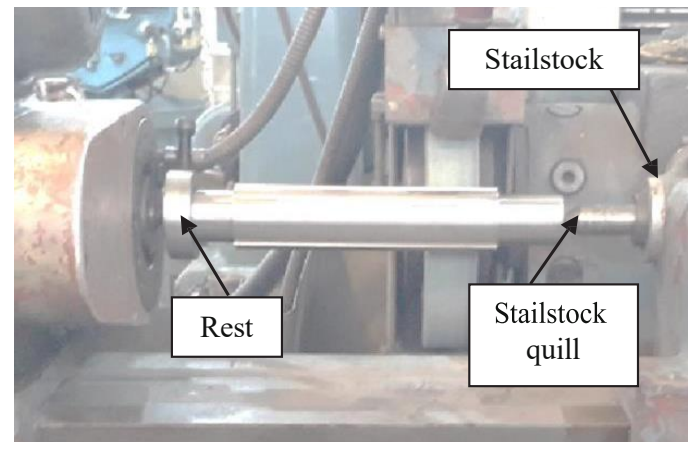

$a$

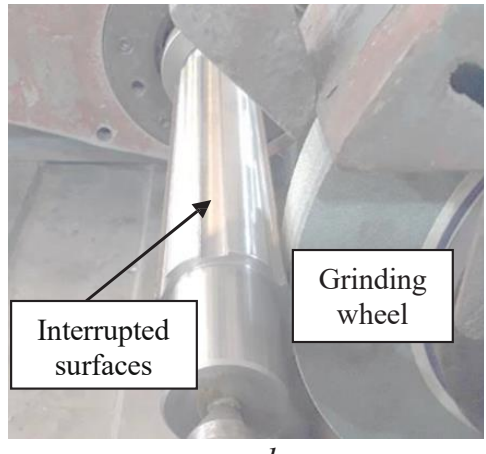

$b$

Fig. 2. Experimental setup for the grinding tests: $a$-view from the front; $b$-view from the side

Surface roughness $(R a)$ of the grinding surface has been measured at least three times on each testing sample using SJ201 surface roughness tester. During the measurement, the standard length of measurement has been set to $0.8 \mathrm{~mm}$, the radius of tip has been $0.005 \mathrm{~mm}$, the measuring direction has been parallel to the sample centerline (i.e. perpendicular to the cutting velocity vector). 
The surface roughness value at each experiment is the average value of consecutive measurements. Mitutoyo Crysta - Plus M544 3D coordinate measuring machine has been used to measure roundness error $(R E)$. Roundness error has been also measured on each sample at least three times at different cross-sections. The roundness error value at each experiment has been also calculated as the average value of consecutive measurements. Multiple measurements per sample (both surface roughness and roundness error) is intended to reduce the effect of measurement errors on measurement results

With four input parameters, each parameter has been selected with three levels of values as shown in Table 1. The selection of value of input parameters has been based on the ability of the experimental machine to adjust those parameters as well as in accordance with several documents [16, 17].

The Taguchi method has been used to design the experimental matrix. If this method has been used in this study, it was because this is the method enabling the design of matrix with a minimum number of experiments but enabling a large number of input parameters, there are many levels of values in each parameter, the values of input parameters do not need to follow any rules, and the parameters can be in qualitative form $[18,19]$. Indeed, with four input parameters, when designing in the form of a Box-Behnken matrix or in the form of Composite Central Design (CCD), a minimum of twenty-five experiments is required, while designing in the form of a full two-level matrix also requires at least sixteen experiments $[20,21]$. On the other hand, the values of abrasive grain size in this study are 46 mesh, 60 mesh and 80 mesh, respectively, where 60 is not the average value of 46 and 80 (i.e. $60 \neq(46+80) / 2$ ). Similarly, with the ability to adjust the spindle speed (workpiece speed), the value of $250 \mathrm{rpm}$ is also not the average value of $165 \mathrm{rpm}$ and $250 \mathrm{rpm}$ (i.e, $250 \neq(165+250) / 2$ ). In this case, other than the Taguchi method can be used, other methods cannot be applied.

Table 1

Input parameters

\begin{tabular}{ccccccc}
\hline \multirow{2}{*}{ Input parameters } & \multirow{2}{*}{ Symbol } & Unit & \multicolumn{3}{c}{ Value at levels } \\
\cline { 4 - 6 } & & & mesh & 46 & 60 & $\mathbf{2}$ \\
Grain size & $G s$ & rpm & 165 & 250 & 80 \\
Workpiece speed & $n_{w}$ & $f_{d}$ & $\mathrm{~mm} / \mathrm{rev}$ & 0.05 & 0.075 & 330 \\
Feed rate & $a_{p}$ & $\mathrm{~mm}$ & 0.01 & 0.015 & 0.09 \\
Depth of cut & & &
\end{tabular}

In fact, with four input parameters, each with three levels of values, when designing by the Taguchi method, there will be two options, on is a matrix of nine experiments, the other is a matrix of twenty-seven experiments. However, the essence of designing the experimental matrix of twenty-seven experiments is the triple repetition of the matrix of nine experiments. This is intended to reduce the effect of random errors during the experiment on outputs [18]. In this study, for the purpose of reducing costs for the experimental process, the nine experiments option has been used. The experimental matrix consisting of nine experiments is shown in Table 2.

In addition to the four input paramenters which will change the value of each parameter at each test as shown in Table 2, the grinding process has been performed with the following conditions:

- cutting velocity: $31.88 \mathrm{~m} / \mathrm{s}$ (the grinder has only one spindle speed of 2,030 rpm);

- dressing the grinding wheel with 1-grain diamond dresser with its symbol of 3908-0088 C

(Russian Federation), dressing depth is $0.01(\mathrm{~mm})$, and dressing feed rate is $120 \mathrm{~mm} / \mathrm{min}$;

- a $10 \%$ aqueous emulsion solution is provided to the grinding zone at a flow rate of 12 liters/min.

\section{Results and discussion}

The test results are shown in Table 2. All surface roughness values in this table are less than $1.6 \mu \mathrm{m}$, which shows that the aluminum oxide grinding wheel with ceramic binder completely meets the requirements of surface roughness when grinding of interrupted surfaces [2]. All values of roundness error in Table 2 correspond to level 5 of it (look up the level of roundness error in accordance with the value of roundness error and the diameter size). This level of roundness error 
is also within the range of it of the workpiece when machining by external cylindrical grinding method (when externally cylindrical grinding, the roundness error is from level 3 to level 6) [22]. This also shows that using an aluminum oxide grinding wheel with ceramic binder also meets the roundness error requirement when grinding of interrupted surfaces.

The grinding experiment in case of continuous surface workpiece has also been conducted in accordance with the matrix in Table 2. The test results are also shown in this table. The results show that both surface roughness and roundness error in interrupted surface grinding are larger than those in continuous surface grinding. In which, the surface roughness in interrupted surface grinding increases by about $50 \%$ compared to that in continuous surface grinding, and it is about $36 \%$ for roundness error.

Table 2

Experimental matrix and results

\begin{tabular}{ccccccccc}
\hline \multirow{2}{*}{ Trial. } & \multicolumn{3}{c}{ Input parameter } & & \multicolumn{2}{c}{$\begin{array}{c}\text { Interrupted surface } \\
\text { workpiece }\end{array}$} & \multicolumn{2}{c}{$\begin{array}{c}\text { Continuous surface } \\
\text { workpiece }\end{array}$} \\
\cline { 2 - 10 } & $\boldsymbol{G s}(\mathbf{m e s h})$ & $\boldsymbol{n}_{\boldsymbol{w}}(\mathbf{r p m})$ & $\boldsymbol{f}_{\boldsymbol{d}}(\mathbf{m m} / \mathbf{r e v})$ & $\boldsymbol{a}_{\boldsymbol{p}}(\mathbf{m m})$ & $\boldsymbol{R a}(\boldsymbol{\mu m})$ & $\boldsymbol{R} \boldsymbol{E}(\boldsymbol{\mu m})$ & $\boldsymbol{R} \boldsymbol{a}(\boldsymbol{\mu} \mathbf{m})$ & $\boldsymbol{R} \boldsymbol{E}(\boldsymbol{\mu m})$ \\
\hline 1 & 46 & 165 & 0.05 & 0.01 & 0.638 & 6.520 & 0.432 & 4.781 \\
2 & 46 & 250 & 0.075 & 0.015 & 0.651 & 6.938 & 0.446 & 5.032 \\
3 & 46 & 330 & 0.09 & 0.02 & 0.648 & 7.292 & 0.410 & 5.325 \\
4 & 60 & 165 & 0.075 & 0.02 & 0.652 & 7.066 & 0.403 & 5.216 \\
5 & 60 & 250 & 0.09 & 0.01 & 0.648 & 6.812 & 0.446 & 4.981 \\
6 & 60 & 330 & 0.05 & 0.015 & 0.518 & 6.832 & 0.362 & 5.062 \\
7 & 80 & 165 & 0.09 & 0.015 & 0.622 & 6.922 & 0.408 & 5.012 \\
8 & 80 & 250 & 0.05 & 0.02 & 0.490 & 6.948 & 0.309 & 4.911 \\
9 & 80 & 330 & 0.075 & 0.01 & 0.512 & 6.775 & 0.366 & 5.428
\end{tabular}

In Fig. 3, 4, respectively, it is Pareto chart of the effect of input parameters on surface roughness and roundness error, in which the significance level has been chosen as 0.05 [23]. At this level of significance, the value of limiting curve (red curve) is 2.78. If the curve of an input parameter exceeds the limit, it is considered that such parameter has a significant effect on responses [23]. Accordingly, abrasive grain size is the parameter having the greatest effect on surface roughness, followed by the effect of feed rate. Workpiece speed has the third greatest effect on surface roughness, while depth of cut has no significant effect on surface roughness. This is explained as follows: The grain size of grinding wheel determines the number of size of scratches left on workpiece surface, so it greatly affects the surface roughness [2, 24]. Changing feed rate and workpiece speed will also change the "stacking» of scratches caused by abrasive grains left on workpiece surface $[2,24]$. Therefore, these two parameters have a great effect on surface roughness. This result is similar to those in several studies $[25,26]$.

For roundness error, all four input parameters significantly affect roundness error. In which, the effect of input parameters on roundness error increases gradually in the order of abrasive grain size, workpiece speed, feed rate and depth of cut. This problem is explained as follows: depth of cut is the parameter directly affecting the component of radial force acting on workpiece suface and material removal rate. When changing the cutting depth, it will change the component of radial force as well as material removal rate, affecting the forming mechanism of workpiece surface, thereby affecting roundness error [27]. The change of feed rate and spindle speed changes the time of radial force acting on workpiece surface, thereby changing the rigidity of workpiece as well as machine, leading to the effect on roundness error [28]. The change of abrasive grain size will also change the depth of cut of abrasive grain left on the workpiece surface, i.e. it also affects the roundness error through the component of radial force. However, since the change in abrasive grain size is much smaller that in the change in depth of cut, the effect of abrasive grain size on roundness error is therefore smaller than that of depth of cut. 


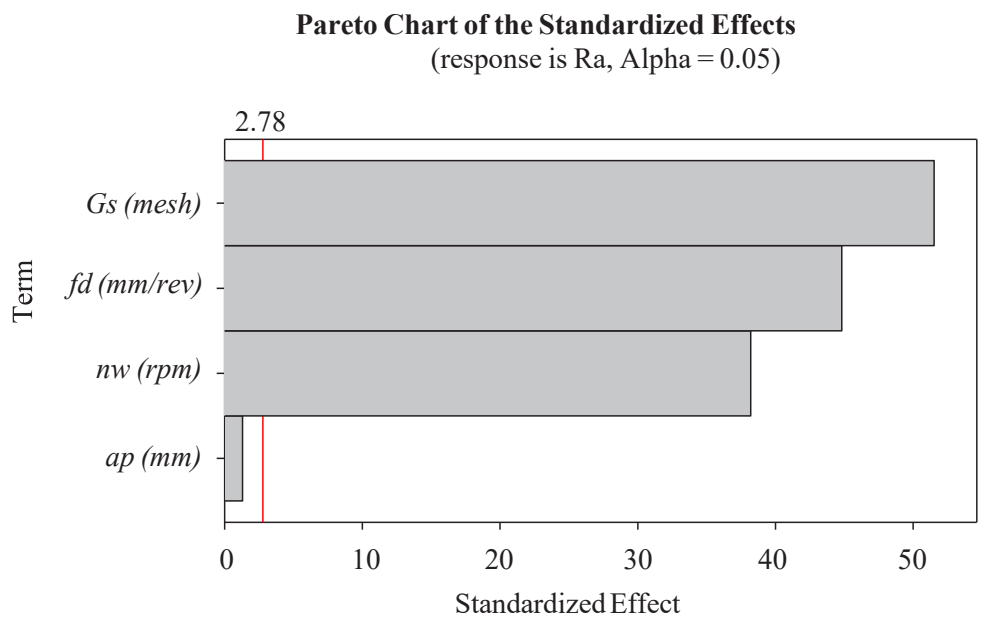

Fig. 3. Pareto chart of the standardized effects for surface roughness

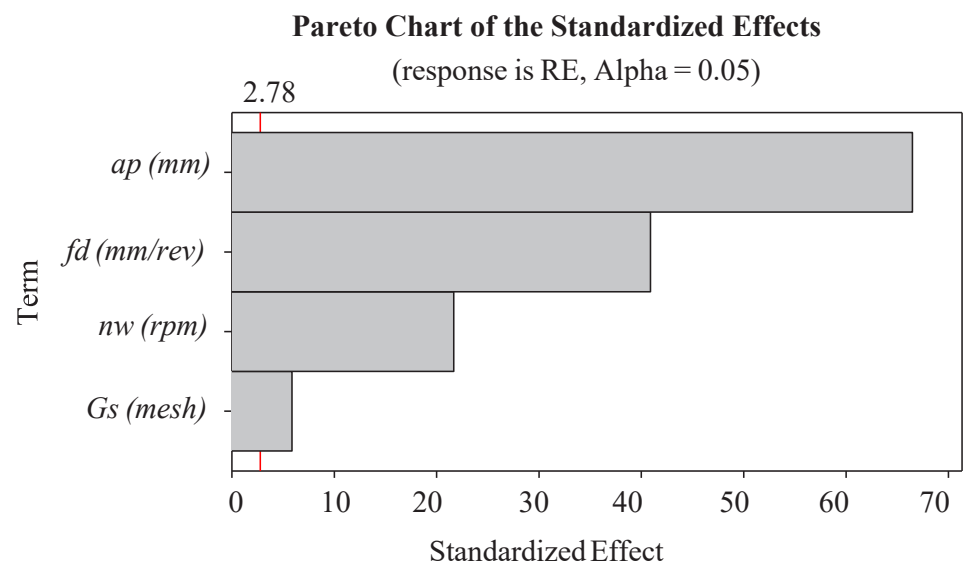

Fig. 4. Pareto chart of the standardized effects for roundness error

Thus, it is possible to see that the effect of input parameters on surface roughness and roundness error is not the same, even opposite. For example, abrasive grain size is the parameter having the greatest effect on surface roughness but it is the parameter having the least effect on roundness error, or depth of cut has the negligible effect on surface roughness, but it is the parameter having the greatest effect on roundness error. This shows that if only observe two Fig. 3, 4, it will cause us a great difficulty and it can be said that it is impossible to determine the values of input parameters to ensure both surface roughness and roundness error with small values. The data in Table 2 shows the smallest surface roughness in experiment No. 8, but the roundness error has the smallest value in experiment No. 1. Thus, observing the datas in Table 2 will also fail to determine the value of input parameters to ensure both surface roughness and roundness error with small values. Therefore, in order to achieve the stated goal of determining input parameters to simultaneously ensure both surface roughness and roundness error with small values, it is necessary to solve the multi-objective problem.

In this study, the DEAR method has been selected to solve the multi-objective optimization problem. This is a simple method, which has been performed in many studies, in many different fields such as multi-objective optimization of turning process [29, 30], multi-objective optimization of EDM machining [31], etc. The steps to follow the DEAR method are as follows [32-34]:

Step 1: at each experiment, weights for the response will be calculated in accordance with (1), (2):

$$
\mathrm{W}_{R a_{i}}=\frac{R a_{i}}{\sum_{i=1}^{m} R a_{i}},
$$




$$
\mathrm{W}_{R E_{i}}=\frac{R E_{i}}{\sum_{i=1}^{m} R E_{i}} .
$$

In which: $R a_{i}$ and $R E_{i}$ are surface roughness and roundness error at experiment $i$, respectively; $m$ is the total number of experiments.

Step 2: calculating the multi response performance index (MRPI) by the following (3):

$$
M R P I=\mathrm{W}_{R a_{i}} \cdot R a_{i}+\mathrm{W}_{R E_{i}} \cdot R E_{i} .
$$

Step 3: corresponding to the level of each input parameter that the value of MRPI at that level is the smallest, such level is considered the best.

Step 4: calculating the difference of the largest MRPI minus the smallest MRPI of each input parameter (Max-Min), which the parameter having the largest value is considered to have the greatest effect on the machining process.

From the experimental data in Table 2, the weights of responses, and the MRPI values at each experiment have been calculated in accordance with the from (1) to (3), as shown in Table 3. From the data in Table 3, the MRPI values of allinput parameters at all levels have been calculated. These values have been calculated as the sum of the MRPI values of each parameter at the respective levels, as shown in Table 4.

Table 3

\begin{tabular}{|c|c|c|c|}
\hline \multirow{2}{*}{ Trial } & \multicolumn{2}{|c|}{ Weight } & \multirow{2}{*}{ MRPI } \\
\hline & $R a$ & $R E$ & \\
\hline 1 & 0.11861 & 0.10498 & 0.76017 \\
\hline 2 & 0.12103 & 0.11171 & 0.85386 \\
\hline 3 & 0.12047 & 0.11741 & 0.93425 \\
\hline 4 & 0.12121 & 0.11378 & 0.88296 \\
\hline 5 & 0.12047 & 0.10969 & 0.82524 \\
\hline 6 & 0.09630 & 0.11001 & 0.80145 \\
\hline 7 & 0.11563 & 0.11146 & 0.84343 \\
\hline 8 & 0.09109 & 0.11188 & 0.82194 \\
\hline 9 & 0.09518 & 0.10909 & 0.78782 \\
\hline
\end{tabular}

Weights of responses and MRPI at experiments

Table 4

Total MRPI values of parameters at the levels

\begin{tabular}{ccccc}
\hline \multirow{2}{*}{ Parameter } & \multicolumn{3}{c}{ Levels } & Max-Min \\
\cline { 2 - 4 } & $\mathbf{1}$ & $\mathbf{2}$ & $\mathbf{3}$ & 0.09509 \\
\hline$G s$ & 2.54827 & 2.50966 & 2.45319 & 0.03696 \\
$n_{w}$ & 2.48656 & 2.50104 & 2.52352 & 0.21935 \\
$f_{d}$ & 2.38356 & 2.52464 & 2.60291 & 0.26594 \\
$a_{p}$ & 2.37322 & 2.49874 & 2.63916 &
\end{tabular}

From the data in Table 4, it shows that the abrasive grain size has the smallest total $M R P I$ value corresponding to level 3, while the remaining three parameters all have the smallest total MRPI value corresponding to level 1. Thus, the optimal value of abrasive grain size is 80 mesh (level 3), of spindle speed is $165 \mathrm{spm}$ (level 1), of feed rate is $0.05 \mathrm{~mm} / \mathrm{rev}$ (level 1), and of depth of cut is $0.01 \mathrm{~mm}$ (level 1). The Max-Min of MRPI value is 0.26594 is biggest, being the depth of cut. Thus, if evaluating the grinding process through two parameters of surface roughness and roundness error, depth of cut is the parameter having the greatest effect on grinding process, 
followed by the effect of feed rate, abrasive grain sive, and spindle speed is the parameter having the least effect on grinding process among the four investigated parameters.

A number of experiments with optimal values of input parameters have been conducted, the results showed that the average values of surface roughness were roundness error are $0.502(\mu \mathrm{m})$ and $6.665(\mu \mathrm{m})$, respectively. When comparing these experimental results with the experimental values in Table 2, it is obvious that the output parameters have been significantly improved.

In this study, only four input parameters were considered, including abrasive grain size, spindle speed, feed rate and depth of cut. Regarding the responses, only surface roughness and roundness error have been considered. Consideration of more input parameters, with more output parameters need to be done in the near future.

\section{Conclusions}

Some conclusions are as follows:

- both surface roughness and roundness error in interrupted surface grinding increase compared to those in continuous surface grinding, specifically, surface roughness increases by about $50 \%$ and roundness error increases by about $36 \%$;

- the aluminum oxide grinding wheel with ceramic binder completely meets the requirements of surface roughness and roundness error when grinding of interrupted surfaces;

- abrasive grain size is the parameter having the greatest effect on surface roughness, followed by the effect of feed rate and workpiece speed. Depth of cut has no significant effect on surface roughness;

- all four parameters have a significant effect on roundness error, in which depth of cut is the parameter with the greatest effect, followed by feed rate, workpiece speed, and finally abrasive grain size;

- if evaluating the grinding process through two parameters of surface roughness and roundness error, depth of cut is the parameter having the strongest effect on grinding process, followed by the effect feed rate, abrasive grain size and workpiece speed;

- in order to simultaneously ensure that surface roughness and roundness error have the same minimum values, the optimal values of abrasive grain size, spindle speed, feed rate and depth of cut are $80 \mathrm{mesh}, 165 \mathrm{rpm}(25.9 \mathrm{~m} / \mathrm{min}), 0.05 \mathrm{~mm} / \mathrm{rev}$, and $0.01 \mathrm{~mm}$, respectively;

- studying the durability of aluminum oxide grinding wheel with ceramic binder to grind the interrupted surface of 20XH3A steel, as well as studying the microstructure of machined surface are the works that the authors of this article will carry out in the near future.

\section{Acknowledgement}

The authors would like to send sincere thanks to Hanoi University of industry for their financial support in the implementation of this study.

\section{References}

[1] Marinescu, I. D., Hitchiner, M. P., Uhlmann, E., Rowe, W. B., Inasaki, I. (2006). Handbook of Machining with Grinding Wheels. CRC Press, 632. doi: https://doi.org/10.1201/9781420017649

[2] Malkin, S., Guo, C. (2008). Grinding technology: Theory and Applications of Machining with Abrasives. New York: Industrial Press.

[3] Diniz, A. E., Gomes, D. M., Braghini, A. (2005). Turning of hardened steel with interrupted and semi-interrupted cutting. Journal of Materials Processing Technology, 159 (2), 240-248. doi: https://doi.org/10.1016/j.jmatprotec.2004.05.011

[4] Diniz, A. E., de Oliveira, A. J. (2008). Hard turning of interrupted surfaces using CBN tools. Journal of Materials Processing Technology, 195 (1-3), 275-281. doi: https://doi.org/10.1016/j.jmatprotec.2007.05.022

[5] Nayak, M., Sehgal, R. (2019). Experiment Modeling of Response Parameters and CBN Tool Wear in Continuous and Interrupted Hard Turning of AISI D6 Steel. Indian Journal of Science and Technology, 12 (19), 1-16. doi: https://oi.org/10.17485/ ijst/2019/v12i19/143902

[6] De Mello, H. J., de Mello, D. R., Rodriguez, R. L., Lopes, J. C., da Silva, R. B., de Angelo Sanchez, L. E. et. al. (2018). Contribution to cylindrical grinding of interrupted surfaces of hardened steel with medium grit wheel. The International Journal of Advanced Manufacturing Technology, 95 (9-12), 4049-4057. doi: https://doi.org/10.1007/s00170-017-1552-y 
[7] Mello, H. J. de, Mello, D. R. de, Bianchi, E. C., Aguiar, P. R. de, D’Addona, D. M. (2015). Grinding of AISI 4340 steel with interrupted cutting by aluminum oxide grinding wheel. Rem: Revista Escola de Minas, 68 (2), 229-238. doi: https://doi.org/ $10.1590 / 0370-44672015680070$

[8] Ribeiro, F. S. F., Lopes, J. C., Garcia, M. V., de Angelo Sanchez, L. E., de Mello, H. J., de Aguiar, P. R., Bianchi, E. C. (2020). Grinding assessment of workpieces with different interrupted geometries using aluminum oxide wheel with vitrified bond. The International Journal of Advanced Manufacturing Technology, 108 (3), 931-941. doi: https://oi.org/10.1007/ s00170-020-05500-w

[9] Rodriguez, R. L., Lopes, J. C., Garcia, M. V., Tarrento, G. E., Rodrigues, A. R., de Ângelo Sanchez, L. E. et. al. (2020). Grinding process applied to workpieces with different geometries interrupted using CBN wheel. The International Journal of Advanced Manufacturing Technology, 107 (3-4), 1265-1275. doi: https://doi.org/10.1007/s00170-020-05122-2

[10] Köklü, U. (2013). Optimisation of machining parameters in interrupted cylindrical grinding using the Grey-based Taguchi method. International Journal of Computer Integrated Manufacturing, 26 (8), 696-702. doi: https://doi.org/10.1080/095119 2x.2012.749537

[11] Otaghvar, M. H., Hahn, B., Werner, H., Omiditabrizi, H., Bähre, D. (2018). A novel approach to roundness generation analysis in centerless through-feed grinding in consider of decisive parameters of grinding gap by use of 3D kinematic simulation. Procedia CIRP, 77, 247-250. doi: https://doi.org/10.1016/j.procir.2018.09.007

[12] Cui, Q., Ding, H., Cheng, K. (2014). An analytical investigation on the workpiece roundness generation and its perfection strategies in centreless grinding. Proceedings of the Institution of Mechanical Engineers, Part B: Journal of Engineering Manufacture, 229 (3), 409-420. doi: https://doi.org/10.1177/0954405414530899

[13] Hänel, A., Teicher, U., Pätzold, H., Nestler, A., Brosius, A. (2017). Investigation of a carbon fibre-reinforced plastic grinding wheel for high-speed plunge-cut centreless grinding application. Proceedings of the Institution of Mechanical Engineers, Part B: Journal of Engineering Manufacture, 232 (14), 2663-2669. doi: https://doi.org/10.1177/0954405417690556

[14] Dap, P., Tuan, N. A. (1983). Machine tool design. Ha Noi: Science and technics publishing House.

[15] Girsang, I. P., Dhupia, J. S. (2014). Machine Tools for Machining. Handbook of Manufacturing Engineering and Technology, 811-865. doi: https://doi.org/10.1007/978-1-4471-4670-4_4

[16] Long, B. T., Luc, T. T., Tuy, T. S. (2011). Principles of material processing. Ha Noi: Science and technics publishing House.

[17] Nee, A. Y. C. (Ed.) (2015). Handbook of Manufacturing Engineering and Technology. Springer, 3500. doi: https://doi.org/ 10.1007/978-1-4471-4670-4

[18] Karna, S. K., Sahai, R. (2012). An Overview on Taguchi Method. International Journal of Engineering and Mathematical Sciences, 1, 11-18. Available at: https://www.academia.edu/27762936/An_Overview_on_Taguchi_Method

[19] Trung, D. D., Thien, N. V., Nguyen, N.-T. (2021). Application of TOPSIS Method in Multi-Objective Optimization of the Grinding Process Using Segmented Grinding Wheel. Tribology in Industry, 43 (1), 12-22. doi: https://doi.org/10.24874/ ti.998.11.20.12

[20] Dean, A., Voss, D., Draguljić, D. (2017). Design and Analysis of Experiments. Springer, 840. doi: https://doi.org/10.1007/ 978-3-319-52250-0

[21] Mathews P. G. (2005). Design of Experiments with MINITAB. ASQ Quality Press Milwaukee, Wisconsin. Available at: https://www.academia.edu/23892705/Design_of_Experiments_with_MINITAB

[22] Loc, N. D., Tien, L. V., Ton, N. D., Viet, T. X. (2010). Handbook of manufacturing technology. Ha Noi: Science and technics publishing House.

[23] Du, N. V., Binh, N. D. (2011). Design of experiment techniques. Ha Noi: Science and technics publishing House.

[24] Rowe, W. B. (2009). Principles of Modern Grinding Technology. William Andrew. Available at: https://www.sciencedirect. com/book/9780815520184/principles-of-modern-grinding-technology

[25] Hung, T. Q., Duc, D. V., Son, N. H. (2018). Optimization of cutting parameters for minimum the surface roughness when grinding SKD11 steel on cylindrical grinder. Proceeding of the 5th National Conference on Mechanical Science \& Technology. Ha Noi. Available at: https://sti.vista.gov.vn/tw/Lists/TaiLieuKHCN/Attachments/294811/41548-325-131388-1-10-20190718.pdf

[26] Soepangkat, B. O. P., Agustin, H. C. K., Subiyanto, H. (2017). An investigation of force, surface roughness and chip in surface grinding of SKD 11 tool steel using minimum quantity lubrication-MQL technique. AIP Conference Proceedings. doi: https:// doi.org/10.1063/1.4985459

[27] Shaw, M. C. (1996). Energy Conversion in Cutting and Grinding*. CIRP Annals, 45 (1), 101-104. doi: https://oi.org/10.1016/ s0007-8506(07)63025-x

[28] Xu, W., Wu, Y., Sato, T., Lin, W. (2010). Effects of process parameters on workpiece roundness in tangential-feed centerless grinding using a surface grinder. Journal of Materials Processing Technology, 210 (5), 759-766. doi: https://doi.org/10.1016/ j.jmatprotec.2010.01.003 
[29] Nguyen Hong, S., Vo Thi Nhu, U. (2021). Multi-objective Optimization in Turning Operation of AISI 1055 Steel Using DEAR Method. Tribology in Industry, 43 (1), 57-65. doi: https://doi.org/10.24874/ti.1006.11.20.01

[30] Obiko, J. O., Mwema, F. M., Bodunrin, M. O. (2021). Validation and optimization of cutting parameters for Ti-6Al-4V turning operation using DEFORM 3D simulations and Taguchi method. Manufacturing Review, 8, 5. doi: https://doi.org/10.1051/ mfreview/2021001

[31] Muthuramalingam, T., Mohan, B. (2013). Multi-Response Optimization of Electrical Process Parameters on Machining Characteristics in Electrical Discharge Machining Using Taguchi-Data Envelopment Analysis-Based Ranking Methodology. Journal of Engineering and Technology, 3 (1), 57. doi: https://doi.org/10.4103/0976-8580.107103

[32] Reddy, V., Reddy, C. S. (2016). Multi Response Optimization of EDM of AA6082 Material using Taguchi- DEAR Method. International Journal of Scientific \& Engineering Research, 7 (6), 215-219. Available at: https://www.ijser.org/researchpaper/ Multi-Response-Optimization-of-EDM-of-AA6082-Material-using-Taguchi--DEAR-Method.pdf

[33] Muthuramalingam, T., Vasanth, S., Mohamed Rabik, M., Geethapriyan, T., Ramamurthy, A. (2016). Multi Response Optimization of EDM Process Parameters using Assignments of Weight Method. International Journal of Engineering Research \& Technology, 4 (26), 1-3. Available at: https://www.ijert.org/research/multi-response-optimization-of-edm-process-parameters-using-assignments-of-weight-method-IJERTCONV4IS26024.pdf

[34] Sandeep, M. J., Manjunath, P. G. C., Chate, G. R., Parappagoudar, M. B., Daivagna, U. M. (2019). Multi Response Optimization of Green Sand Moulding Parameters Using Taguchi-DEAR Method. Applied Mechanics and Materials, 895, 1-7. doi: https://doi.org/10.4028/www.scientific.net/amm.895.1

Received date 15.09.2021

Accepted date 01.12.2021

Published date 10.01.2022
(C) The Author(s) 2021

This is an open access article under the Creative Commons CC BY license

How to cite: Trung, D. D., Ha, L. D. (2022). Research on selection of abrasive grain size and cutting parameters when grinding of interrupted surface using aluminum oxide grinding wheel with ceramic binder. EUREKA: Physics and Engineering, 1, 93-102. doi: https://doi.org/10.21303/2461-4262.2022.002058 